Filol. Linguíst. Port., Sáo Paulo, v. 17, n. 2, p. 333-352, jul./dez. 2015

http://dx.doi.org/10.11606/issn.2176-9419.v17i2p333-352

\title{
Processos e mudanças em abreviaturas mineiras setecentistas: regularidade e ruptura
}

Processes and changes in Minas Gerais' 18th century abbreviations: regularity and rupture

\author{
Sueli Maria Coelho*
}

Universidade Federal de Minas Gerais, Belo Horizonte, Minas Gerais, Brasil Jania Martins Ramos

Universidade Federal de Minas Gerais, Belo Horizonte, Minas Gerais, Brasil Aléxia Teles Duchowny

Universidade Federal de Minas Gerais, Belo Horizonte, Minas Gerais, Brasil

\begin{abstract}
Resumo: Este trabalho analisou abreviaturas de documentos setecentistas escritos no Arraial do Tijuco, hoje cidade de Diamantina-MG. Cotejaramse recursos braquigráficos empregados em compromissos de irmandades religiosas de estratos sociais distintos para testar duas hipóteses: (i) as abreviaturas refletem diferenças diastráticas e, portanto, (ii) permitem identificar o grau de letramento do escrevente. As análises empreendidas não atestam a correção das hipóteses, mas as generalizaçōes alcançadas sinalizam que as abreviaturas, como qualquer outro fenômeno linguístico, sofrem processos de mudança sistemáticos, organizados e múltiplos, diferentemente do que prevê a parca literatura sobre o tema.
\end{abstract}

Palavras-chave: Abreviaturas. Português de Minas Gerais. Século XVIII.

\begin{abstract}
This study analyzed 18th century abbreviations from documents written in Arraial do Tijuco, today Diamantina, in Minas Gerais, Brazil. Brachygraphic resources used in religious brotherhoods' commitments from different social strata were compared to test two hypotheses: (i) abbreviations
\end{abstract}

* Professoras da Faculdade de Letras da Universidade Federal de Minas Gerais, Belo Horizonte, Minas Gerais, Brasil, su.coelho@uol.com.br, jania.ramos@gmail.com, alexiateles@hotmail.com, respectivamente. 
reflect differences between strata and therefore (ii) they allow identifying the degree of literacy of writing subjects. The analysis undertaken do not attest the correctness of assumptions, but the generalizations reached indicate that abbreviations, as any other linguistic phenomenon, suffer systematic, organized and multiple change processes, a different result from those that the meagre literature on the subject provides.

Keywords: Abbreviations. Minas Gerais Portuguese. 18th century.

\section{CONSIDERAÇÓES INICIAIS}

O emprego de abreviaturas em textos de sincronias pretéritas, mais especificamente dos séculos XVIII e XIX, tem fomentado pesquisas e, consequentemente, trazido contribuiçóes para o entendimento de alguns fenômenos linguísticos, além, é evidente, de fazer emergir novas questōes sobre um tema relativamente pouco explorado. As diferentes formas de abreviar uma mesma palavra ou expressão espelham processos de mudança, tais como o de gramaticalização (Chaves, 2006; Cohen, 2008). A possibilidade de se recorrer às abreviaturas como instrumental heurístico para caracterizar sociolinguisticamente os escreventes tem sido aventada por pesquisadores como Barbosa (2013) e Carneiro et al. (2013).

Esses novos olhares para os recursos braquigráficos são de extrema relevância para os estudos linguísticos, sobretudo para os de cunho variacionista, para os quais é tão cara a imbricação de fatores linguísticos e extralinguísticos, nos processos de variação e mudança. Aqueles que se debruçam sobre os manuscritos, tomando-os como fonte de dados para a interpretação de fenômenos de mudança linguística, sabem o quanto é importante e, principalmente, difícil, caracterizar social e culturalmente a mão que empunhou a pena. Aspectos como grau de letramento ${ }^{1}$ e a atividade profissional do escrevente ${ }^{2}$ são de fundamental importância para

1 Por letramento entenda-se "um processo de aprendizagem social e histórica da leitura e da escrita em contextos informais e para usos utilitários, por isso é um conjunto de práticas, ou seja, letramentos [...] Distribui-se em graus de domínio que vão de um patamar mínimo a um máximo." (Marcuschi, 2001, p. 21-22). Sobre os graus identificados nesta pesquisa, conferir tabelas 1,2 , e 3 .

2 Esses dois parâmetros visam à descrição do perfil socioeconômico dos "informantes" de nossa amostra, composta por escrivães de Irmandades mineiras do século XVIII. Em amostras sociolinguísticas contemporâneas, Labov (2001) argumenta em favor da adoção de

Coelho, S.M.; Ramos, J.M.; Duchowny, A.T. Processos e mudanças em abreviaturas mineiras... 
orientar a análise dos dados, quando se deseja, por exemplo, cotejar línguas que exibem certo parentesco ou ainda interpretar um fenômeno de mudança, já que os pressupostos da sociolinguística variacionista (Labov, 1972) atestam que tais fenômenos tendem a ser desencadeados a partir de estratos mais inferiores na hierarquia social.

No intuito de contribuir com pesquisadores que visam a desenvolver metodologias para trabalhos com corpora, o presente artigo busca testar as seguintes hipóteses: (a) as abreviaturas espelham diferenças diastráticas; e, portanto, (b) podem constituir um recurso que auxiliará o estudioso do manuscrito a precisar o grau de letramento do escrevente. Essas hipóteses surgiram a partir da verificação de que os documentos das diferentes irmandades analisadas apresentam diferenças em relação à frequência e aos tipos de abreviaturas - conferir Duchowny, Coelho e Coelho, 2014, doravante DCC (2014). Para a verificação das hipóteses, vamos, inicialmente, definir abreviatura e resenhar os resultados obtidos por DCC (2014) em sua análise sobre os estatutos de quatro irmandades mineiras, escritos em Diamantina, antigo Arraial do Tijuco, Comarca do Serro Frio, estado de Minas Gerais, na segunda metade do século XVIII. Esse conteúdo constitui o cerne da seção 1 . Na seção 2, discutiremos o perfil do escrivão. Na terceira, faremos o cruzamento de dados entre tipo de abreviatura e grupo social que produziu o texto, utilizando os resultados apresentados na primeira seção, e discutiremos a tipologia adotada, propondo ajustes nos parâmetros de análise. $\mathrm{Na}$ seção 4, discutiremos propostas a favor de que o uso das abreviaturas se transforma de modo sistemático e, na última, apresentaremos nossas conclusóes.

\section{2 (RE)LENDO AS ABREVIATURAS DOS COMPROMISSOS DE IRMANDADES MINEIRAS}

O termo abreviatura, que tem como base de formaçáo a palavra breve, do latim brevis (cf. Cunha, 1982), constitui um recurso linguístico metonímico na medida em que designa parte de uma palavra escrita cuja significação compreende toda a palavra. Segundo Aulete (1980, p. 25), "a abreviatura consta de sinais,

três parâmetros para a construçáo de um índice socioeconômico para estabelecer categorias discretas como indicadores individuais: (i) ocupação profissional, (ii) escolarização, (iii) valor da residência. A aplicação desses parâmetros a "informantes" do século XVIII, em análise aqui, requereu adaptaçóes.

Coelho, S.M.; Ramos, J.M.; Duchowny, A.T. Processos e mudanças em abreviaturas mineiras... 
letras ou fraçôes de palavras: usa-se nos calendários, nas fórmulas médicas, na química, na botânica, nas matemáticas, no tratamento que damos às pessoas a quem escrevemos".

Ao tentar identificar o que motivaria a presença de abreviaturas em um texto, DCC (2014) enumeram três explicaçóes já defendidas por estudiosos do assunto e formulam uma quarta: (1) as abreviaturas tornam a escrita mais rápida e concisa (Megale e Toledo Neto, 2005); (2) a frequente repetição de uma mesma palavra gera o hábito de ler por seus elementos determinantes e a abreviatura se resume a tais traços, tornando a leitura mais rápida (Núñez, 1994); (3) o formato e a frequência das abreviaturas resultam do entrecruzamento de tempo, moda e exigência do médium pelo qual se veicula a palavra (Barroca, 2000); e (4) o emprego de abreviaturas constitui uma maneira de adornar um texto, dando mostras de que o escrevente domina o estilo da época (DCC, 2014). Apesar de alguns defenderem que o uso de abreviaturas visa à economia, quer de espaço e tinta, quer de tempo, isso não é consensual entre todos os estudiosos da questão, principalmente se considerarmos que algumas se tornam menos econômicas que as palavras que elas representam, como esta, extraída do Estatuto da Ordem Terceira de São Francisco: Acompanham ${ }^{\text {to }}$ - Acompanhamento.

É possível depreender certa complementaridade entre as explicaçóes de (1) a (4) ora apresentadas. A primeira é de natureza pragmática, a segunda, cognitiva e, as duas últimas, sociais, por correlacionarem os fatores moda, tempo, atitude e médium. Se tais explicaçóes são adequadas, poderemos depreender delas algo sobre o perfil social ${ }^{3}$ do escrevente que faz uso de abreviaturas: ele domina a escrita, na medida em que poderá executar sua tarefa com rapidez e concisão, restringindose aos elementos determinantes das palavras (2); é um bom leitor, na medida em que é capaz de construir seu texto em consonância com outros da época, além de sensível às especificidades do médium utilizado (3). Já a interpretação referente ao adornamento do texto acrescenta um elemento novo, que manifesta atitude positiva em relação às abreviaturas, podendo levar a diferenças significativas quanto ao número de ocorrências nos diferentes textos.

Tendo em conta tal complexidade, reanalisaremos os resultados apresentados por DCC (2014) sobre um corpus formado por compromissos de irmandades

3 O termo perfil social corresponde à identificação do estatuto socioeconômico do "informante" a partir dos parâmetros letramento, cargo ocupado na mesa da Irmandade e situaçáo financeira, esta inferida a partir do valor em ouro das doaçóes exigidas pela Irmandade, e do número de missas a serem celebradas post-mortem.

Coelho, S.M.; Ramos, J.M.; Duchowny, A.T. Processos e mudanças em abreviaturas mineiras... 
religiosas. Esses contêm "leis que regulam as práticas das associações religiosas, firmando direitos e deveres de seus membros", assim como seu perfil social (DCC, 2014, p. 240). As irmandades em questão são: Nossa Senhora das Mercês (a partir de agora, NSMercês - manuscrito redigido em 1778); Nossa Senhora do Amparo (NSAmparo - manuscrito redigido em 1782); Santíssimo Sacramento (SSacramento - único documento impresso na Oficina Tipográfica de Lisboa em 1783); e Ordem Terceira de São Francisco (SFrancisco - manuscrito redigido em 1788). A primeira, conforme prevê seu próprio compromisso, aceita homens "brancos, pardos ou pretos de Guiné" como irmãos. Entretanto o juiz e o escrivão devem ser "crioulo[s]" e o tesoureiro deve ser "branco, abonado". O compromisso de NSAmparo indica que o irmão pode ser do sexo masculino ou feminino e ser maior de idade com até 40 anos. O documento do SSacramento caracteriza seus membros de forma ainda mais sucinta: o irmáo pode ser secular ou eclesiástico, desde que seja pessoa "honrada" e de "aprovados costumes". Finalmente, a Ordem de SFrancisco permite a entrada de pessoa honesta, sem vício e indicada por três irmãos. Vê-se, pela descrição apresentada, que as duas primeiras irmandades se integram por homens mulatos e negros e que, as outras duas, por homens brancos e economicamente abastados, o que sugere, ao menos, dois estratos sociais: (i) um composto por classes sociais mais populares - Irmandades de Nossa Senhora das Mercês e de Nossa Senhora do Amparo - e (ii) outro representativo da elite Irmandade do Santíssimo Sacramento e Ordem Terceira de São Francisco.

DCC (2014) descrevem todas as abreviaturas dos documentos citados, chegando a um total de 1.054 ocorrências. Acompanhando tipologia proposta por Miralles Carlo (1929), adaptada e modificada por Costa (2006), categorizam as abreviaturas por tipo e quantificam suas ocorrências. A Tabela 1 apresenta, entre parênteses, o total de ocorrências (tokens) por classe e, sem parênteses, o total de tipos (types): 
Tabela 1 - Tipos de abreviaturas ${ }^{4}$

\begin{tabular}{c|c|c|c|c|c|c|c|c}
\hline $\begin{array}{c}\text { Documento/ } \\
\text { Abreviatura }\end{array}$ & DEV & NSM & NSA & SSA & SFR & REF & Total & $\%$ \\
\hline $\begin{array}{c}\text { Letra } \\
\text { sobrescrita }\end{array}$ & $\begin{array}{c}49 \\
(140)\end{array}$ & $\begin{array}{c}92 \\
(203)\end{array}$ & $\begin{array}{c}108 \\
(231)\end{array}$ & $2(3)$ & $\begin{array}{c}131 \\
(452)\end{array}$ & $6(6)$ & $388(1035)$ & $73,6(60,2)$ \\
\hline Sigla simples & $1(1)$ & $19(68)$ & $7(99)$ & $2(2)$ & $\begin{array}{c}19 \\
(202)\end{array}$ & $8(10)$ & $56(382)$ & $10,6(22,2)$ \\
\hline Suspensão & $2(2)$ & $13(45)$ & $8(14)$ & - & $5(89)$ & $2(2)$ & $30(152)$ & $5,8(8,8)$ \\
\hline Contração & $6(12)$ & $10(14)$ & $5(5)$ & - & - & $3(6)$ & $24(37)$ & $4,6(2,2)$ \\
\hline Mista & $1(75)$ & $7(11)$ & $3(4)$ & - & $2(2)$ & $2(2)$ & $15(94)$ & $2,9(5,5)$ \\
\hline Sinal especial & $1(1)$ & $4(7)$ & - & $1(2)$ & $1(1)$ & - & $7(11)$ & $1,3(0,6)$ \\
\hline Numérica & - & $3(3)$ & $1(1)$ & - & $1(1)$ & - & $5(5)$ & $0,9(0,3)$ \\
\hline $\begin{array}{c}\text { Letra } \\
\text { reduplicada }\end{array}$ & - & - & - & - & $2(4)$ & - & $2(4)$ & $0,3(0,2)$ \\
\hline Total & $\begin{array}{c}60 \\
(231)\end{array}$ & $\begin{array}{c}148 \\
(351)\end{array}$ & $\begin{array}{c}132 \\
(354)\end{array}$ & $\mathbf{5 ( 7 )}$ & $\begin{array}{c}161 \\
(751)\end{array}$ & $21(26)$ & $527(1720)$ & $100(100)$ \\
\hline$\%$ & $\begin{array}{c}11,4 \\
(13,4)\end{array}$ & $\begin{array}{c}28,1 \\
(20,4)\end{array}$ & $\begin{array}{c}\mathbf{2 5 , 0} \\
(\mathbf{2 0 , 6 )}\end{array}$ & $\begin{array}{c}0,9 \\
(0,4)\end{array}$ & $\begin{array}{c}30,6 \\
(43,7)\end{array}$ & $\begin{array}{c}4,0 \\
(1,5)\end{array}$ & & $100(100)$ \\
\hline
\end{tabular}

Fonte: DCC (2014, p. 242-243, Tabela 1)

DCC (2014) compararam as frequências de cada tipo de abreviatura por irmandade e verificaram que NSMercês e NSAmparo apresentam quase duas vezes mais abreviaturas do que a Ordem Terceira de SFrancisco e quase seis vezes mais do que o SSacramento. Observam que as classes de abreviaturas descritas na primeira coluna podem ser hierarquizadas, como se vê a seguir, tomando como parâmetro a "necessidade de conhecimentos específicos do copista para empregar abreviaturas que contêm em si mais informaçóes e, por isso, seriam mais independentes do contexto" (DCC, 2014, p. 247):

(1) Numérica $\rightarrow$ Letra sobrescrita $\rightarrow$ Contração $\rightarrow$ Suspensão $\rightarrow$ Sigla simples $\rightarrow$ Letra reduplicada $\rightarrow$ Sinal especial (DCC, 2014, p. 246).

4 DEV refere-se aos termos de devassa analisados pelos autores que, por serem de outro gênero textual, não foram aqui analisados.

Coelho, S.M.; Ramos, J.M.; Duchowny, A.T. Processos e mudanças em abreviaturas mineiras... 
Segundo interpretação dos autores, as classes mais à direita em (1) "exigiriam do copista [e do leitor] maior letramento" (DCC, 2014, p. 247), aparecendo exemplificadas em (2):

$$
\text { (2) } 7 b r o \rightarrow \text { Prov }^{o r} \rightarrow \text { Pl. } \rightarrow \text { Ord. } \rightarrow N . \rightarrow \text { V. CC. } \rightarrow X p^{o}
$$

(Respectivamente setembro, provedor, provincial, ordem, nossalo/s ou número, Vossas senhorias e Cristo.)

DCC (2014) verificaram que, no continuum (1), as duas classes mais à direita são mais frequentes nos compromissos das irmandades de NSAmparo e de NSMercês (respectivamente 6,18\% e 6,80\%) do que nos compromissos de SSacramento $(1,22 \%)$ e da Ordem Terceira de São Francisco (3,73\%). Observaram, ainda, que, no SSacramento, há apenas seis abreviaturas, em um total de 5.850 palavras, isto é, apenas $0,12 \%$. Já nos três compromissos manuscritos, há 441 delas, em um total de 31.084 palavras, com uma média de 5,6\%. Vê-se, pois, que o fato de o texto ser impresso, como é o caso de SSacramento, altera fundamentalmente o uso de abreviaturas. Por essa razão, para fins de verificaçấo de nossas hipóteses, vamos eliminar da análise os dados referentes a esse documento. Excluídos, é possível reorganizar as abreviaturas e sua relaçáo de dependência ou náo com o contexto da seguinte forma:

\section{Tabela 2 - Correlaçáo entre a (in)dependência das abreviaturas em relaçáo ao contexto e o perfil social dos "informantes"}

\begin{tabular}{|c|c|c|c|c|c|c|}
\hline Irmandade & \multicolumn{2}{|c|}{$\begin{array}{l}\text { Abreviaturas } \\
\text { dependentes }\end{array}$} & \multicolumn{2}{|c|}{$\begin{array}{c}\text { Abreviaturas } \\
\text { independentes }\end{array}$} & \multirow{2}{*}{\multicolumn{2}{|c|}{ Total }} \\
\hline & $\mathrm{N}$ & $\%$ & & & & \\
\hline $\begin{array}{c}\text { Elite } \\
\text { (SFrancisco) }\end{array}$ & 3 & 2,3 & 132 & 97,76 & 134 & \\
\hline $\begin{array}{c}\text { Outras } \\
\text { (NSMercès e NSAmparo) }\end{array}$ & 4 & 1,92 & 204 & 98,08 & 208 & \\
\hline Total & 7 & & 336 & & 342 & \\
\hline
\end{tabular}

Coelho, S.M.; Ramos, J.M.; Duchowny, A.T. Processos e mudanças em abreviaturas mineiras... 
As abreviaturas dependentes do contexto, as numéricas e as de letras sobrescritas, apresentam maior legibilidade, demandando menor esforço e menos conhecimento prévio por parte do leitor e do escrevente, sendo também mais subordinadas a escolhas subjetivas. Já as independentes do contexto, as de letras reduplicadas e de sinal especial, são menos legíveis, exigindo, por conseguinte, maior grau de letramento e esforço dos usuários.

Pautando-se tanto por critérios de natureza quantitativa quanto históricosociais, DCC (2014, p. 248) argumentam sobre a necessidade de se considerar que "o emprego das abreviaturas, para além de economia de tempo e de espaço, visava a embelezar o texto, dando mostras de que seu escrevente conhecia o estilo da época”. Tal inferência implica admitir que os escrivães das irmandades de pardos e negros tinham o seguinte perfil: tinham mãos inábeis, quando comparados aos de irmandades de brancos, o que poderia indicar também graus de letramento distintos, principalmente se considerarmos que, segundo relatam estudiosos da história mineira, muitos pardos e negros eram alfabetizados nas próprias irmandades, que cumpriam também relevante papel social no período setecentista de Minas Gerais.

Perante tais resultados e interpretaçóes, podemos levantar algumas questóes: (i) existe, de fato, um padrão em relação aos resultados quantitativos obtidos?; (ii) por que DCC (2014) não consideraram suficiente a explicação do "padrão" em termos da distinção entre texto manuscrito e texto impresso?-Neste artigo vamos, pois, retomar os dados analisados pelos autores e tentar mostrar que, pelo menos do ponto de vista quantitativo, não há um padrão. Além disso, intentamos refutar a conclusão de que o emprego das abreviaturas no período constituía uma forma de adornar o texto e de assinalar o pertencimento a um grupo social mais elitizado tanto do ponto de vista econômico quanto intelectual. Nossa argumentação se apoia no perfil do escrivão delineado nos próprios documentos analisados. Embora no compromisso de NSMercês (e em sua Reforma) tenha a exigência de que o escrivão fosse "crioulo", o mesmo náo se nota nos compromissos da Ordem Terceira de SFrancisco e no do SSacramento. Ademais, os requisitos quanto às habilidades e ao grau de dificuldade das tarefas executadas pelos escrivães eram semelhantes nas quatro irmandades, conforme se buscará demonstrar na próxima seção. 


\section{DO PERFIL DO ESCRIVÃO}

No livro de compromisso de NSMercês, lê-se que o escrivão será eleito todos os anos juntamente com um juiz, e um tesoureiro sob os seguintes critérios:

elegendo-se todos os annos hum Juiz, e hum | Escrivão amboz Crioulos, eoTezoureirohomembranco, e abonado, | havendo mais dois Procuradores, e hum Zelador, e também duas Juizas, eduas Procuradoras, Como doze Mordomos, le outras tantas Mordomas" (NSMercês, linhas 325-330, grifo nosso).

Tal restrição é mantida na Reforma do Compromisso da Irmandade de NSMercês. A exigência de que o tesoureiro seja abonado evoca alguma atenção, pois, embora não explicitada, parece aplicar-se também ao escrivão, uma vez que ele pode substituir o tesoureiro em várias situaçôes e representá-lo na Mesa. As contribuiçôes pecuniárias estabelecidas para ambos os cargos eram também semelhantes. Nos excertos em que são enumeradas as tarefas concernentes ao escrivão e ao tesoureiro, nota-se, em várias passagens, complementaridade e sobreposiçóes, conforme se atesta a seguir:

(a) Cobrança das contribuiçôes aos irmãos

Depois de feitas as e $=\mid$ leiçoens $\mid$ logo noprimeiro Domingo se ajuntarão os Irmaons | novos, e velhos, edaráo os velhos contas individuaes das $\mid$ despezasquesefi zerão no annopreterito, e achando-se, que as $\mid$ contas são liquidas sefará termo no Livro da receita, e des= $\mid$ peza, e havendo algum alcan-se noz officiaes que acabarão disto $\mid$ mesmo se fará declaraçáo aonovo Tezoureiro para cobrar, | e arecadar no termo de quinze dias, e não pagando os devedores, | ou devedor, tirará oTezoureiroMonitorio contra osdevedores, pelo | principal, e custas, o que será dentro em hummêz, e náo cumprindo | assim | o Escrivão the carregará a dividacomoseja | estivesse recebida, eos Procuradores daráo conta de tres em tres me $\mid$ zes à nova Irmandade (NSMercês, inhas 350-360, grifo nosso).

(b) Representação de outros membros da Mesa nas reuniôes

Coelho, S.M.; Ramos, J.M.; Duchowny, A.T. Processos e mudanças em abreviaturas mineiras... 
Sucedendo porem estar auzente qual quer dos Irmaons Juiz, ou Menzarioz | em tal cazo sempre sefaráMeza com os Irmaons que existirem | naterra, eestaMeza assim feita será valioza, etudo | quanto de ter minarem na Meza que sefizersefara termo | pello Escrivão para que atodootempo conste da decisão | que houve a respeito da materia proposta em cada respecti $=\mid$ vaMeza (NSMercês, linhas 405-410).

No impedimen $=\mid=$ to do Thesoureiro, fará as suas vezes o Escriváo. $\mathrm{O}$ Th e $=\mid$ =soureiro não pagará joia alguma em virtude do seu trabalho. (Reforma, NSMercês, linhas 148149, grifo nosso).

(c) Contribuição financeira

O Juiz dara de esmolla em cada humanno depois de acabar o Cargo, a quantia de doze oitavas de oiro, eaJuiza dará outra tanta esmolla, eoEscriváo dará Seis oitavas assim tambem| Tezoureiro (...) Os Menzarioscadahum dará de esmollatresoitavas de oiro eo Irmão | quesequizer remir dará dezaseis oitavas de oiro (NSMercês, linhas 550-555, grifo nosso).

Diante das exigências relatadas, pode-se depreender que escrivão e tesoureiro tinham não apenas obrigações semelhantes, como também deveriam, necessariamente, ter posses equivalentes para arcarem com os custos dos anuais, o que nos leva a inferir que ambos pertenciam ao mesmo estrato social.

(d) Realização de tarefas de escrituração

Ficará a seu [do Escrivão] cuidado fazer os lançamentos da Receita e Despesa, os termos da entrada dos irmãos, das actas das Mesas, Offi cios ou cartas da Irman $=\mid=$ dade, que deverão ser assignados pelo Juiz, Thesoureiro e pelo mesmo Escrivão; tomar conhecimento de todas as questóes, que disserem respeito á Irmandade, para dellas informar a Mesa, e trazer sempre bem calculadas as possibilidades da $\mathbf{I r}=$ mandade, para esta náo se arriscar a despesas superiores ás suas forças ou posses (Reforma NSMercês, linhas 163169 , grifo nosso).

[O tesoureiro] dando parte emMeza, enelaaprezentará | asContasdoquesegastar, etera cuidado deaplicaraoProcurá 
| dor para Cobrar oque sedeveaIrmandade, easistiráatodos os actos | dela para ter prontamente oquefor necesario, etodoodinheiro que | [lh] epararnamam será obrigado arecolher ao Cofre, oqual te $=\mid$ ratrez chaves, dasquaesg oardaráúmaomesmoTezoureiro, outra $\mid$ o Juiz, eoutra o Escrivaó, e para odito Cargo sedeve eleger sugei= | to idôneo (NSAmparo, linhas 64-71, grifo nosso).

(e) Habilidades ou qualidades

AobrigaçaódoEscrivaónaódeMenoscontahe, porque aele pertence ocuidado | dos Livros, eboa Ordem deles, fazendo a cen $[t]$ os de recei $=\mid$ ta, edespezacomclareza, edestinçaó; equando o Juiz poralgua | ocupasaó, ouempedimentonaó possa ase $[s]$ tiroqueesta aseu cargo | eobrigaçaõ, o Escrivaó suprirá emseu lugar, comomesmo | ônus do Capitulo terceiro (NSAmparo, linhas 52-59, grifo nosso).

Atuação nas eleições da nova Mesa

As eleiçóes para Juiz, Thesoureiro, Escrivão e Procura= $=$ dor seráo feitas pela maneira seguinte: No dia determi $=$ =nado para este fi $\mathrm{m}$, que será a vespera da festividade da Irmandade, se reuniráo os Mesarios, mais irmáos e o $\mathrm{Pa}=$ =rocho da Freguezia ou quem as suas vezes fizer, que será previamente avisado, a fi $\mathrm{m}$ de a ellas assistir como repre $=$ sentante da autoridade diocesana.

O Escrivão de accordo com o Juiz, apresentará, particularmente, antes da Mesa $\mid$ uma lista de tres ou dois nomes ao Parocho (...) Os novos empregados da $\mathbf{I r}=\mid$ =mandade, irmãos e irmãs de Mesa, Juizes e Juizas seráo esco $=\mid=$ lhidos pelo Escriváo de accordo com o Juiz e Thesoureiro, e ap $=\mid=$ provados por acclamação dos irmaos presentes. Uma lista | desta eleição assignada pelo Parocho, ou quem suas vezes | fizer e pelo Escrivão será affixada em logar patente em nos= $\mid$ saCapella (NSMercês, linhas 227 260, grifo nosso). 
(f)Atuação nas festas

No dia da Festa de Nossa Senhora, o Juiz, o Tesoureiro, e demais irmáos deveráo trazer joias e anuais e entregá-los aos membros da Mesa, que faráo os lançamentos. Fica o escrivão, assim como o Procurador, isento (NSMercês, linhas 303-308, grifo nosso)

Neste dia da festa de Nossa Senhora tambem os irmáos deverão trazer as suas | joias e annuáes, e para o fi $\mathbf{m}$ de os receber, o Juiz, Thesoureiro e $\mid$ Escrivão se reuniráo em Mesa com os livros respectivos $\mathrm{pa}=\mid=$ ra que se possam fazer immediatamente os lançamentos dos $\mid$ dinheiros recebidos, e ahi se conservarão por todo tempo necessario (Reforma NSMercês, linhas 320-325, grifo nosso).

O Escriváo e o Procurador da Irman $=\mid$ dade seráo isemtos do pagamento de joias em rasáo do seu mui= | to trabalho (Reforma NSMercês, linhas 320-325, grifo nosso).

Por fim, observem-se as quantias de doação previstas para cada membro, bem como o número de missas por sua alma, em caso de falecimento:

Asesmolas, quede $=\mid$ vem dar os OfeciaesdeMeza, saó as seguintes: Será |obrigado oJuizadardeSeujuizadoVintesinco oitavas de |Ouro, o Escrivaódezaceis, o Tezoureiro doze, eos Irmãos deMeza |quatro Oitavas cadahum, atendendoseasdespezas que |sefazem com asMissas, eCarestias das festas, que tudo seintregará |aoTezoureiro para recolher ao Cofre da Irmandade (NSAmparo, linhas 142-149, grifo nosso).

Pelaalmadetodo o= $\mid$ Irmaóquefalecer, semandaraó logo dizer dentro do Oitavario |Vinte Missas, etendo servido os Cargos, deJuizsemandaraó |dizer trinta, deEscrivaó, ouTezoureiroVinteSinco, comabrevidade mais | possível (NSAmparo, linhas 231-245, grifo nosso)

Sua assistencia, ouConsentimento: Que as esmólas, |e[E] ntradas, declaradas nos Capitulosoutavo, undécimo, |decimo terseiro, edécimoquarto, porseremOpressivas, |fi caráo reduzidas, as do Juiz, eJuiza a $\operatorname{dez}[a]$ seis outavas, |as do Escrivaóadés, as do[Th] ezoureiroaOutto, as dos Mor $=\mid$ domoz, eMordomasatresouttavas, as entradas dos 
$\mathrm{Ir}=\mid$ maoz a humaoutava, as dosquequizerem entrar na $\mathrm{Ir}=\mid$ mandade já enfermoz a dose outavas, a s do acompa= |nhamentoComCrus, eEsquife a Seis Outavas, enaó hin 16= (NSAmparo, linhas 355-364, grifo nosso).

A Irmandade mandará celebrar pela alma decada |hum Irmaó que falecer doze Missas; seporem tiver servido o |Cargo de Th e[s] oureiro, ou Escrivaócelebrar-se-haó de[s] eseis e o |Juiz, ou Juiza vinte, ficando por esta forma alterados os Capitulosdos Estatutos desta Irmandade sobre os objetos | deque trataó os presentes Artigos (NSAmparo, linhas 540-545, grifo nosso).

Dadas as exigências em relação às atividades na Mesa, o total de doaçóes e o número de missas em caso de falecimento, pode-se concluir que o perfil social do escrivão era semelhante ou pouco superior ao do tesoureiro, ou seja, o escrivão deveria ser

homem abonado, idôneo, ter bôalettra e conhecer alguma cousa de escripturaçáo, para ter em bôa ordem, clareza e limpeza os livros da Irmandade [...] trazer sempre bem calculadas as possibilidades da Irmandade, para esta não se arriscar a despesas superiores ás suas forças ou posses (Reforma NSMercês, linha 163-169, grifo nosso).

Do ponto de vista de seu perfil sociolinguístico, o escrivão das irmandades analisadas seria, portanto, um homem detentor de algumas posses, letrado e possivelmente pertencente à elite local. Ainda que as diferentes irmandades acolhessem integrantes de estratos sociais distintos, estamos assumindo, com base no perfil sociolinguístico ora delineado, que as mãos que deixaram suas marcas na escrita dos compromissos eram igualmente hábeis, isto é, pertenciam a pessoas letradas. Assim, a comparação das diferenças braquigráficas irá nos informar, portanto, sobre diferenças entre brancos letrados e pardos ou negros letrados, já que, conforme demonstrado, havia a exigência de cor nos livros de compromissos das diferentes irmandades.

Uma consequência desse reconhecimento do perfil do escrivão, depreendido do texto dos próprios compromissos analisados, leva-nos, se não a descartar, pelo menos a questionar a hipótese de que o escrivão se valia do emprego de recursos braquigráficos como uma marca identitária de pertença a determinado estrato social. 
Definido o perfil social dos copistas, estamos em condiçóes de buscar outra explicação para a diferença numérica de abreviaturas entre os compromissos das irmandades, que não aquelas endossadas e aquela proposta por DCC (2014). Retomando os dados dispostos na Tabela 1 , notamos que há sobreposição tipológica entre as classes que aparecem na primeira coluna. Tais problemas serão objeto de análise na próxima seção.

\section{CRÍTICAS À TIPOLOGIA DA TABELA 1}

DCC (2014) apresentam oito classes de abreviaturas: (i) letra sobrescrita, (ii) sigla simples, (iii) suspensão, (iv) contração, (v) mista, (vi) sinal especial, (vii) numérica e (viii) letra reduplicada. Essas classes resultam da síntese de três estudos: Barroca (2000), Costa (2006) e Spina (1994). Sob o rótulo de letras sobrescritas (classe i), incluem-se abreviaturas que sofreram contração (classe iv). Nas siglas simples (classe ii), o processo é de suspensão (classe iii) ou de contração (classe iv), assim como nas siglas reduplicadas (classe viii). Tais sobreposiçóes impedem avaliar quantitativamente as classes, pois uma mesma ocorrência pode se incluir em uma ou em outra (por exemplo, $V^{\text {cia }}$ é suspensão e letra sobrescrita). Uma solução seria retornar a uma tipologia mais próxima daquela elaborada por Miralles Carlo (1929).

1. Suspensão: queda de segmento final da palavra

1.1 Sigla: abreviatura de uma só letra

1.2 Suspensão propriamente dita: abreviatura composta de mais de uma letra

2. Contração: queda de segmento no meio da palavra e manutenção do final da palavra

2.1 Numérica

2.2 Contração propriamente dita

3. Sinal especial

3.1 Sinal com valor universal

3.2 Sinal com valor específico

3.3 Letra reduplicada

Eliminadas as sobreposiçóes, chegamos a uma tipologia mais econômica, composta de três classes e de cinco subclasses. Poderemos, agora, comparar 
quantitativamente as abreviaturas extraídas das produçóes escritas das Irmandades estudadas, analisando os resultados dispostos na Tabela 3:

\section{Tabela 3 - Frequência de ocorrências conforme as subclasses de abreviaturas}

\begin{tabular}{|c|c|c|c|c|c|c|}
\hline \multirow{2}{*}{\multicolumn{2}{|c|}{$\begin{array}{c}\text { Irmandades } \\
\text { Tipo de abreviatura }\end{array}$}} & \multicolumn{2}{|c|}{ Elite } & \multicolumn{2}{|c|}{ Outras } & \multirow[t]{2}{*}{ Total } \\
\hline & & N. & $\%$ & N. & $\%$ & \\
\hline Suspensão & $\begin{array}{c}\text { - Resta } 1 \text { letra } \\
\text { - Resta mais de } 1 \\
\text { letra }\end{array}$ & $\begin{array}{c}202 \\
91\end{array}$ & $\begin{array}{l}53,29 \\
53,84\end{array}$ & $\begin{array}{c}177 \\
78\end{array}$ & $\begin{array}{l}46,70 \\
46,15\end{array}$ & $\begin{array}{l}379 \\
169\end{array}$ \\
\hline Contração & $\begin{array}{l}\text { Numérica } \\
\text { Não numérica }\end{array}$ & $\begin{array}{c}1 \\
452\end{array}$ & $\begin{array}{l}20,00 \\
49,29\end{array}$ & $\begin{array}{c}4 \\
465\end{array}$ & $\begin{array}{l}80,00 \\
50,71\end{array}$ & $\begin{array}{c}5 \\
917\end{array}$ \\
\hline Sinal especial & & 5 & 41,66 & 7 & 58,33 & 12 \\
\hline & tal & 751 & & 731 & & 1.482 \\
\hline
\end{tabular}

A diferença percentual, quando há suspensão e resta uma letra, é de seis pontos percentuais e, quando resta mais de uma, é de sete pontos percentuais em favor da irmandade de elite. No que diz respeito à contração, há de se analisar os dois subtipos. Quando é numérica, nota-se um percentual de uso mais elevado nas irmandades de pardos e crioulos $(80,00 \%)$ e, quando não numérica, o percentual de uso é muito semelhante $(49,29 \%$ e 50,71\%), o que parece sinalizar que há padróes inerentes às próprias abreviaturas que as tornam mais ou menos frequentes em função, talvez, de seu grau de (in)dependência do contexto. No que diz respeito ao sinal especial, também se verifica uma diferença significativa entre as irmandades de perfil socioeconômico mais ou menos elitizado, já que, nas irmandades representativas da elite, o índice percentual é de 41,66\%, contra $58,33 \%$ no outro estrato. Como interpretar tais resultados que, aparentemente, mostram-se tão contraditórios? Conforme a classe de abreviaturas, ora uma ora outra irmandade exibem padrões de uso mais acentuados do ponto de vista percentual? Não haveria uma regularidade que permitisse extrair alguma generalizaçáo a respeito do fenômeno? 
A chave para a solução do problema se evidencia, contudo, quando apresentamos, em formato de gráfico, os resultados referentes às Irmandades de elite.

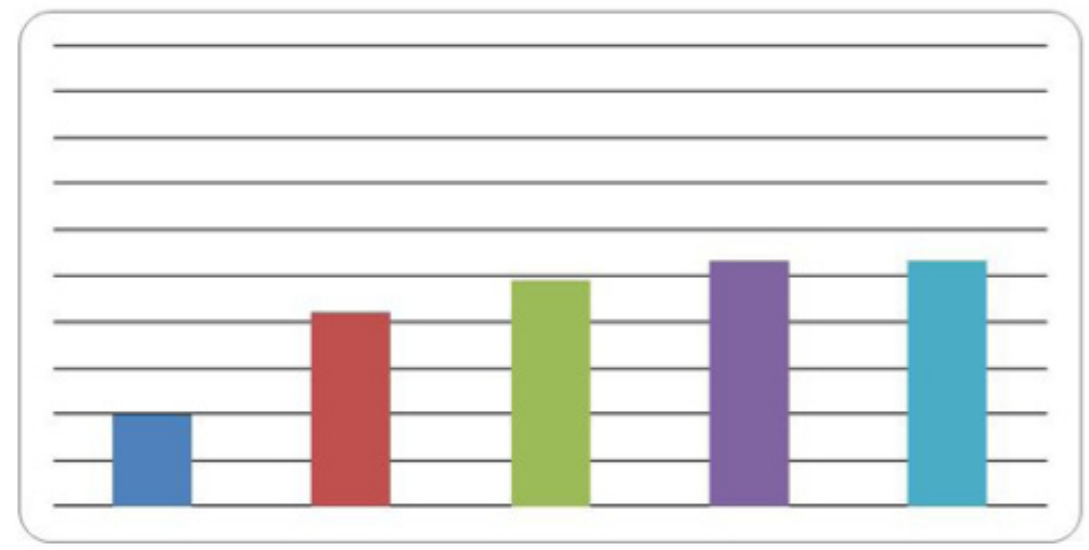

Gráfico 1 - Percentual das ocorrências das diferentes classes de abreviaturas em estatutos de irmandades que congregavam membros da elite local.

O que há de mais importante nesse gráfico não é o perfil de cada processo em separado, mas a tendência que ele aponta. Essa tendência fica mais evidente se tivermos em conta que, segundo estudiosos de questóes braquigráficas (cf. González, 2002; Chaves, 2006), a contração numérica é encontrada em textos mais antigos e que a não numérica, em textos mais recentes. Além disso, a suspensão com mais de uma letra e aquela com apenas uma letra, isto é, a sigla, também apresentam o mesmo padrão. Em outras palavras, o percurso delineado espelha o processo de transformação na forma de se abreviarem palavras, conforme se detalha na próxima seção.

\section{MUDANÇA DE USO NAS ABREVIATURAS: SISTEMATICIDADES NO EIXO TEMPORAL}

González (2002) analisa as abreviaturas da expressão nominal "New York" e identifica uma mudança gradual de sua grafia. Os seguintes estágios são identificados pelo autor: a forma mais antiga é $N$. Y., que contém letras maiúsculas separadas por ponto e espaço. A forma subsequente mantém as mesmas letras em maiúsculas e o ponto, mas o espaço é suprimido. Na etapa posterior, mantêm-se 
as mesmas letras em maiúsculas, suprimindo-se o ponto e o espaço. De fato, é esta a forma mais moderna, uma sigla:

(5) New York > N. Y. > N.Y. > NY

As razóes desse percurso, segundo o autor, seriam explicadas pela necessidade de uma grafia que não fosse confusa e que estabelecesse um paralelo com a compreensão semântica.

Chaves (2006, p. 76, Quadro 4) aplica a hipótese da evolução histórica proposta por González (2002) a um conjunto de formas da expressão nominal Vossa Mercê em cartas brasileiras do século XIX. O resultado é a identificação de um percurso semelhante, só que formalmente mais rico, conforme se vê em (6):

(6) $\mathrm{VM}^{\text {ces }}>\mathrm{VM}^{\text {ce }}>\mathrm{VM}>\mathrm{Vm}^{\text {ces }}>\mathrm{Vm}^{\text {ce }}>\mathrm{Vm}^{\text {ce }}>\mathrm{Vm}^{\mathrm{e}}>\mathrm{Vm}^{\text {" }}>\mathrm{Vm}>\mathrm{vm}^{\text {ces }}$ $>\mathrm{vm}^{\mathrm{ce}}>\mathrm{vm}^{\mathrm{e}}>\mathrm{vm}^{5}$

Inicialmente, tem-se a letra inicial maiúscula de cada palavra que compóe a expressão nominal, e a última sílaba da expressão aparece sobrescrita. A seguir, aparece maiúscula apenas a letra inicial da primeira palavra. Depois, a parte sobrescrita vai sofrendo supressões até desaparecer. Ao final, as letras iniciais tornamse minúsculas. Em síntese, o seguinte trajeto de uso de recursos braquigráficos foi documentado por Chaves (2006), conforme o item que foi desaparecendo:

(7) acentos $>$ cedilhas $>$ aspas simples $>$ aspas duplas $>$ letra sobrescrita $>$ ponto abreviativo $>$ letra normal $>$ maiúsculas

Os dois trabalhos reforçam a hipótese de que as abreviaturas, como qualquer outro fenômeno linguístico, estão sujeitas a mudanças de modo sistemático.

Analisemos agora o Gráfico 2, em que são comparadas as Irmandades de elite e as de pardos e crioulos, tentando identificar alguma semelhança entre os dados obtidos.

5 A escala (6) reúne os tipos de abreviaturas presentes no corpus analisado por Chaves (2006). A partir desse conjunto, é possível depreender competiçôes entre pares de formas, como $\left[\mathrm{VM} / \mathrm{VM}^{\mathrm{CE}}\right],[\mathrm{Vm} / \mathrm{vm}]$, dentre outros. 


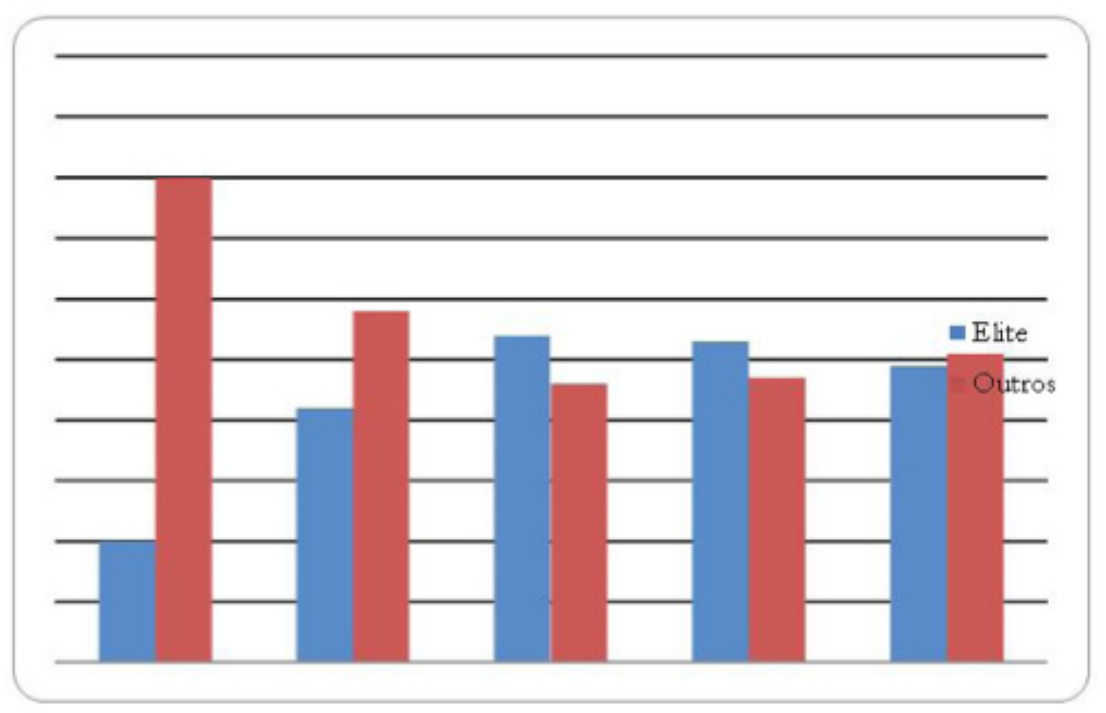

Gráfico 2 - Relação entre os tipos de abreviaturas e os tipos de irmandades

Nas colunas que retratam a contração numérica e o sinal especial, há maiores diferenças de uso nas irmandades de pardos e de crioulos. Essas são as classes das abreviaturas cujos formatos são os mais antigos. Nos demais pares de colunas, as diferenças não são significativas. Desse modo, é razoável deduzir que as Irmandades de pardos e de crioulos são mais conservadoras que as de elite, que, do ponto de vista dessa mudança linguística, mostra-se mais inovadora. Encontra-se aí, portanto, a chave para a aparente contradição dos resultados identificados na Tabela 3.

\section{CONSIDERAÇÓES FINAIS}

Este trabalho elegeu como objeto de estudo recursos braquigráficos coletados em estatutos de Irmandades religiosas mineiras, escritos no último quartel do século XVIII, no antigo Arraial do Tijuco, Comarca do Serro Frio, hoje, Diamantina. A partir da releitura de um estudo de DCC (2014), buscamos verificar a adequação de duas hipóteses: (i) a de que as abreviaturas são sensíveis à variação diastrática, podendo, portanto, (ii) evidenciar características sociolinguísticas do escrivão, por exemplo, maior ou menor grau de letramento. Analisamos dados de quatro compromissos de Irmandades, assim caracterizados: (i) um impresso (SSacramento) 
e outro manuscrito (SFrancisco), ambos de irmandades de brancos, representando a elite da época, e (ii) dois, também manuscritos (NSAmparo e NSMercês), representantes de outra classe social, composta por crioulos e pardos.

Nossos resultados permitem concluir que não há grandes diferenças entre os perfis sociais dos escrivães das irmandades analisadas, já que, segundo informaçôes extraídas dos próprios documentos, exigia-se deles habilidade e conhecimento para cuidar dos livros e fazer anotaçôes claras e legíveis. Além disso, também se exigia desempenho e contribuiçóes semelhantes às do tesoureiro, necessariamente, conforme prescrito no documento, homem branco abonado. A hipótese inicial de que haveria diferenças sociais entre os escrivães teve que ser, portanto, descartada. Assim, a diferença numérica detectada num primeiro momento quanto ao maior ou menor emprego de sinais braquigráficos foi atribuída ao médium de veiculação dos compromissos, se impressos ou manuscritos, o que nos levou a desconsiderar, na análise quantitativa empreendida para julgamento da hipótese, as seis ocorrências de abreviaturas identificadas no documento impresso.

A categorizaçáo tipológica adotada por DCC (2014) e composta de oito tipos de abreviatura foi recategorizada de modo mais sistemático e econômico, indicando-se três processos maiores: (i) suspensão, (ii) contração e (iii) sinal especial. Nossos resultados permitiram identificar um processo de mudança nos modos de abreviar, cuja sistematicidade confirma que, no eixo temporal, tal processo se assemelha a outros de natureza estritamente linguística. Resta-nos, contudo, debruçar-nos sobre os dados com vistas a identificar os fatores que motivaram a mudança linguística iniciar-se nos textos das irmandades que agregavam membros da elite e não naqueles das irmandades que agregavam membros dos estratos sociais inferiores.

\section{REFERÊNCIAS}

Aulete C. Dicionário contemporâneo da Língua Portuguesa. Rio de Janeiro: Delta; 1980.

Barbosa AG. Perfis sócio-históricos de redatores do século XIX: graus de letramento e ortografia. Seminário Nacional do Projeto para a História do Português Brasileiro; 13-14 out, Maceió; Brasil. 9;2013.

Barroca M. Epigrafia medieval portuguesa (862-1422). Vol. 1. Porto: Fundação Calouste Gulbenkian; 2000.

Carneiro Z, Oliveira K, Lobo T. Metodologia para a identificação de perfis socioculturais de redatores em corpora históricos: pesquisa direta em arquivos. Seminário Nacional do Projeto para a História do Português Brasileiro; 13-14 out, Maceió; Brasil. 9;2013. 
Chaves E. Implementação do pronome Você: a contribuição das pistas gráficas [dissertação]. Belo Horizonte: Faculdade de Letras, Universidade Federal de Minas Gerais; 2006.

Cohen MA. Reexame de um caso clássico à luz de novos dados: a gramaticalização e a reanálise de mente. In: Vitral L, Coelho SM, organizadores. Estudos de processos de gramaticalização em português: metodologias e aplicaçóes. Campinas, SP: Mercado de Letra; 2010; p. 57-74.

Costa R. Abreviaturas: simplificação ou complexidade da escrita? 2006. Disponível em: <http://www.historica.arquivoestado.sp.gov.br/materias/anteriores/edicao15/materia01/>. Acesso em: 12 abr. 2014.

Cunha AG. Dicionário etimológico Nova Fronteira da Língua Portuguesa. Rio de Janeiro: Nova Fronteira; 1982.

Duchowny A, Coelho SM, Coelho GH. Sistema de abreviaturas de documentos adamantinos setecentistas. Revista Letras. 2014 jul./dez. 90: 233-252.

González FR. Variación tipográfica en el uso de las “abreviaturas”. 2002. Disponível em: <http://www.ucm.es/info/especulo/cajetin/abreviat.html> Acesso em: 06 dez. 2015.

Labov W. Principles of Linguistic Change: social factors. Vol.2. Oxford: Blackwell Publishers Ltd; 2001.

Labov W. Sociolinguistic Patterns. Philadelphia: University of Pennsylvania Press; 1972.

Marcuschi LA. Da fala para a escrita: atividades de retextualização. São Paulo: Cortez; 2001.

Megale H, Toledo Neto S., organizadores. Por minha letra e sinal. Cotia: Ateliê; 2005.

Millares Carlo A. Paleografía española: Ensayo de una historia de la escritura en España desde el siglo VIII al XVII. Colección Labor: Ciencias históricas. Barcelona: Labor; 1929.

Núñez Contrera L. Manual de paleografía. Madrid: Cátedra; 1994.

Santos M. Da Visigótica à Carolina - a escrita em Portugal de 882 a 1172. Lisboa: Fundação Calouste Gulbenkian; 1994.

Spina S. Introdução à edótica. Crítica textual. São Paulo: Ars Poética; Edusp; 1994.

Recebido em: 06/10/2015

Aceito em: 06/12/2015

Coelho, S.M.; Ramos, J.M.; Duchowny, A.T. Processos e mudanças em abreviaturas mineiras... 